\title{
Correction to: The practice of emergency radiology throughout Europe: a survey from the European Society of Emergency Radiology on volume, staffing, equipment, and scheduling
}

\author{
Mariano Scaglione ${ }^{1,2,3} \cdot$ Raffaella Basilico $^{4}$ - Andrea Delli Pizzi ${ }^{4} \cdot$ Francesca lacobellis $^{5}$ (D) Elizabeth Dick ${ }^{6}$. \\ Stefan Wirth ${ }^{7}$. Ulrich Linsenmaier ${ }^{8} \cdot$ Cem Calli $^{9} \cdot$ Ferco H. Berger $^{10} \cdot$ Koenraad H. Nieboer $^{11}$. Ana Blanco Barrio ${ }^{12}$. \\ Maureen Dumba ${ }^{6} \cdot$ Roberto Grassi $^{13} \cdot$ Katarzyna Katulska $^{14} \cdot$ Gerd Schueller $^{15} \cdot$ Michael N. Patlas $^{16} \cdot$ Andrea Laghi $^{17}$. \\ Mario Muto ${ }^{18} \cdot$ Refky Nicola $^{19}$ - Marc Zins ${ }^{20}$ - Vittorio Miele ${ }^{21} \cdot$ Richard Hartley $^{1,2}$ • Douglas S Katz ${ }^{22}$. \\ Lorenzo Derchi ${ }^{23,24}$
}

Published online: 8 December 2020

(C) European Society of Radiology 2020

\section{Correction to: European Radiology} https://doi.org/10.1007/s00330-020-07436-x

The original version of this article, published on 05 November 2020, unfortunately contained a mistake. The following correction has therefore been made in the original:

The spelling of Michael N. Patlas' name was incorrect. The corrected author list is given above. The original article has been corrected.

Publisher's note Springer Nature remains neutral with regard to jurisdictional claims in published maps and institutional affiliations.

The online version of the original article can be found at https://doi.org/ 10.1007/s00330-020-07436-x

Francesca Iacobellis

iacobellisf@gmail.com 


\section{Affiliations}

\section{Mariano Scaglione ${ }^{1,2,3} \cdot$ Raffaella Basilico $^{4}$ - Andrea Delli Pizzi ${ }^{4}$. Francesca lacobellis ${ }^{5}$ (D) Elizabeth Dick ${ }^{6}$. Stefan Wirth ${ }^{7}$. Ulrich Linsenmaier ${ }^{8}$. Cem Calli ${ }^{9}$. Ferco H. Berger ${ }^{10}$ - Koenraad H. Nieboer ${ }^{11}$. Ana Blanco Barrio ${ }^{12}$. Maureen Dumba ${ }^{6}$. Roberto Grassi ${ }^{13} \cdot$ Katarzyna Katulska $^{14} \cdot$ Gerd Schueller $^{15} \cdot$ Michael N. Patlas $^{16} \cdot$ Andrea Laghi $^{17}$. Mario Muto ${ }^{18} \cdot$ Refky Nicola $^{19} \cdot$ Marc Zins $^{20} \cdot$ Vittorio Miele $^{21} \cdot$ Richard Hartley $^{1,2} \cdot$ Douglas S Katz $^{22}$. Lorenzo Derchi ${ }^{23,24}$}

1 Department of Radiology, James Cook University Hospital, Middlesbrough, UK

2 School of Health and Life Sciences, Teesside University, Middlesbrough, Tees Valley, UK

3 Department of Radiology, Pineta Grande Hospital, Castel Volturno, CE, Italy

4 Department of Neuroscience Imaging and Clinical Science, Gabriele D’Annunzio University, Chieti, Italy

5 Department of General and Emergency Radiology, “Antonio Cardarelli” Hospital, Antonio Cardarelli St 9, 80131 Naples, Italy

6 Department of Radiology, Imperial College Healthcare NHS Trust, St Mary's Hospital, London, UK

7 Department of Radiology and Nuclear Medicine, Schwarzwald-Baar Hospital, Klinikstr. 11, 78052 Villingen-Schwenningen, Germany

8 Institute for Diagnostic and Interventional Radiology, HELIOS Klinikum Munich West and Munich Perlach, Munich, Germany

9 Radiology Department, Ege University Faculty of Medicine, Izmir, Turkey

10 Department of Medical Imaging, Sunnybrook Health Science Centre, University of Toronto, 2075 Bayview Avenue, Toronto, ON M4N 3M5, Canada

11 Departement of Radiology, Vrije Universiteit Brussel (VUB), Universitair Ziekenhuis Brussels (UZ Brussel), Laarbeeklaan 101, 1090 Brussels, Belgium

12 Servicio de Radiodiagnóstico, Sección de Radiología de Urgencias, Hospital G.U. Morales Meseguer, Av. Marqués de los Vélez s/n, 30008 Murcia, Spain
13 Department of Radiology, University of Campania "Luigi Vanvitelli”, Piazza Miraglia 2, 80138 Naples, Italy

14 Department of Radiology, Poznan University of Medical Sciences, Poznan, Poland

15 ERS Emergency Radiology Schueller, 6302 Zug, Switzerland

16 Department of Radiology, Hamilton General Hospital, 237 Barton Street East, Hamilton, Ontario L8L 2X2, Canada

17 Department of Surgical and Medical Sciences and Translational Medicine, "Sapienza" - University of Rome, Sant'Andrea University Hospital, Rome, Italy

18 Department of Neuroradiology, "Antonio Cardarelli” Hospital, Antonio Cardarelli St 9, 80131 Naples, Italy

19 Department of Radiology, SUNY-Upstate University and Medical Center, Syracuse, NY, USA

20 Radiology Department, Groupe Hospitalier Paris Saint Joseph, Paris, France

21 Department of Radiology, Azienda Ospedaliero-Universitaria Careggi, Florence, Italy

22 Department of Radiology, NYU Wintrop Hospital, Mineola, NY, USA

23 Department of Health Sciences, Radiology Section, University of Genoa, Genoa, Italy

24 Department of Emergency Radiology, San Martino Policlinico Hospital, Genoa, Italy 